\section{Duchenne type muscular dystrophy and consanguinity: difficulties in pedigree analysis}

SUMMARY We report the case of a 2-year-old girl who had signs of Duchenne type muscular dystrophy on clinical, electromyographic, laboratory, and pathological examination. The parents of the child are first cousins. A brother and nephew of the mother also had Duchenne type muscular dystrophy.

Karyotype analysis in the proband showed both $\mathrm{X}$ chromosomes to be morphologically normal. The mother had very high plasma CK levels, equivalent to those observed in carriers of the disease.

We discuss different hypothetical mechanisms designed to account for the family pedigree.

The present case study involves a young girl with a normal karyotype who had progressive Duchenne type muscular dystrophy. The parents were consanguineous. $\mathrm{X}$-linked recessive transmission of the myopathy was noted in maternal relatives. This observation raises difficult problems in genetic counselling.

\section{Case report}

A 10-month-old girl was referred to the Pediatric and Medical Genetic Service of Marseille (Professor F. Giraud) for problems in upbringing. The proband was the first child of a marriage between first cousins. This was the first time they had sought genetic counselling, though a brother and a nephew of the mother had Duchenne type muscular dystrophy. The mother of the proband was at first considered to be a possible carrier (Fig. 1). In view of the family history, plasma creatine kinase (CK) and aldolase levels were measured in the mother, father, and child. Plasma CK values were $52 \mathrm{mIU} / \mathrm{ml}$ in the father, $318 \mathrm{mIU} / \mathrm{ml}$ in the mother, and $2840 \mathrm{mIU} / \mathrm{ml}$ in the proband.

Plasma aldolase was $3.8 \mathrm{mIU} / \mathrm{ml}$ in the mother and $40 \mathrm{mIU} / \mathrm{ml}$ in the daughter. We concluded that the mother was a true carrier, the father was normal, and the daughter had muscular dystrophy.

When re-examined at the age of 23 months, the girl walked with difficulty and had hypertrophied calves.

Electromyography detected abnormalities in the triceps muscle. A muscle biopsy specimen was obtained for light microscope and histochemical studies. Some fragments in isopentane were frozen with liquid nitrogen, others were fixed in glutaraldehyde for electron microscopy. Muscle fibres were of unequal size on haematoxylin and eosin staining. Diffuse atrophy was widespread, but a few hypertrophic muscle fibres were seen. In the sarcolemma, numerous nuclei were observed, some of which were centrally positioned. Degenerative changes (Fig. 2) were frequently seen as necrotic foci surrounded by macrophages. Segmentation was detected in the hypertrophic structures.

A few basophilic fibres containing large centrally placed nuclei were seen. Connective tissue was abnormally abundant in the endo- and perimysial spaces. Vascular wall morphology appeared normal

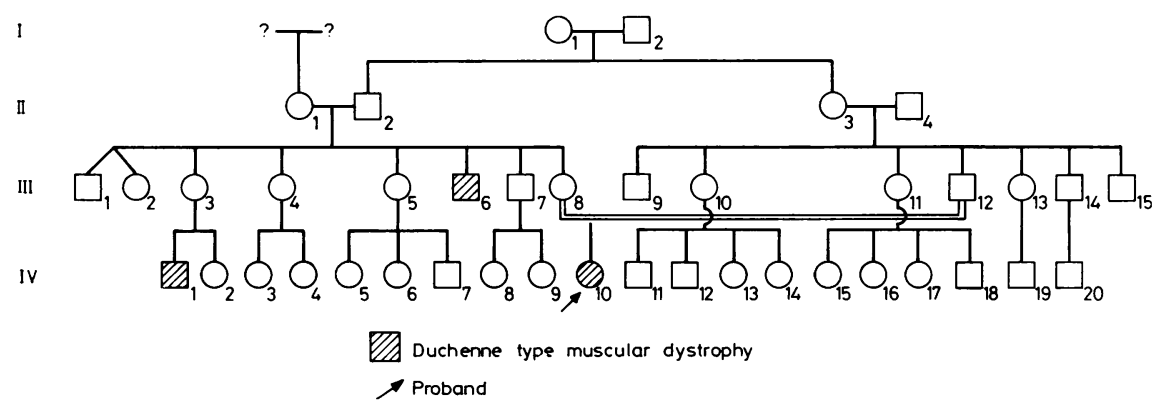

Fig. 1 Family pedigree. 

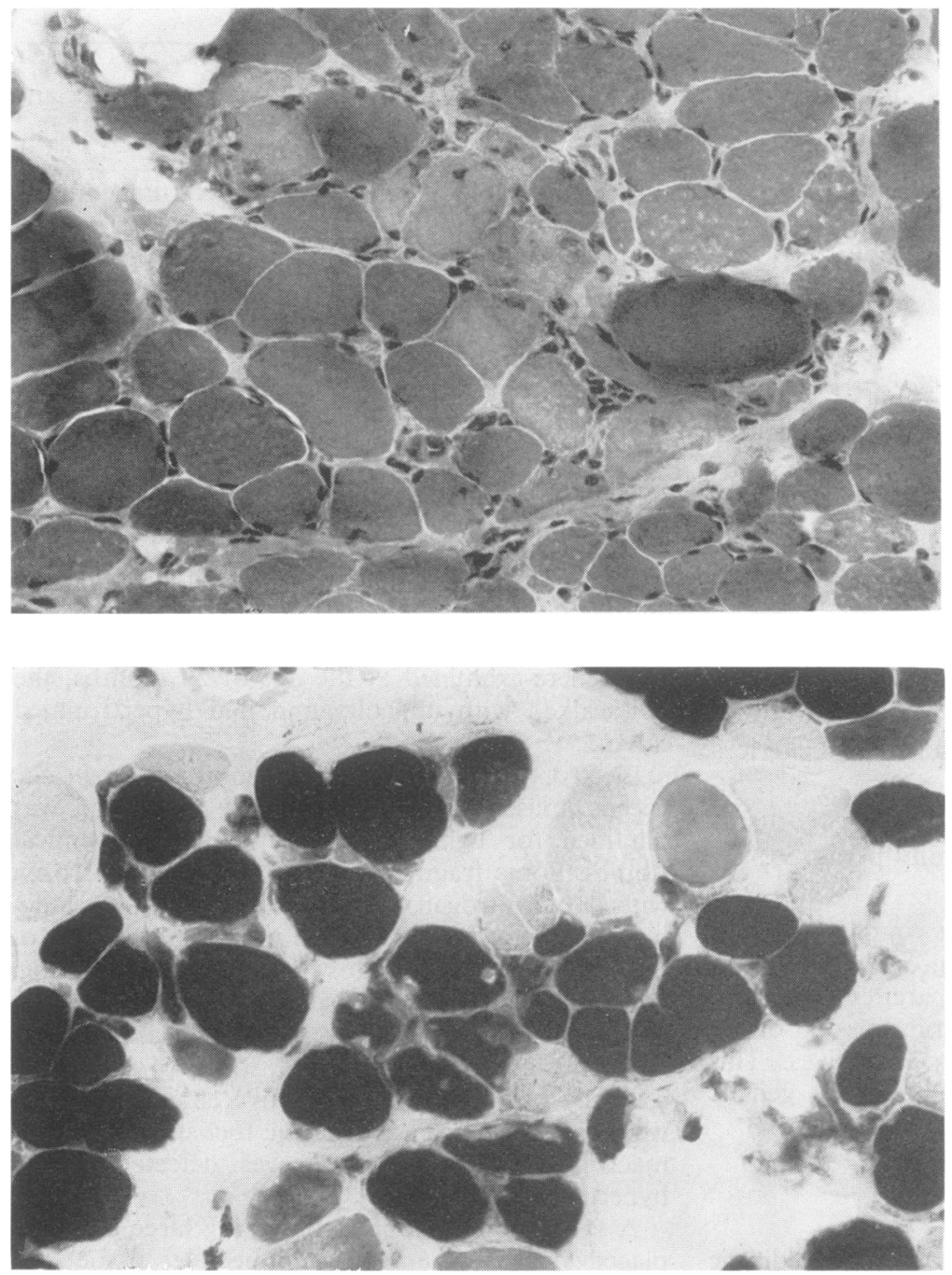

Fig. 2 Markedly unequal size of muscle fibres, several of which display necrosis. Increased number of nuclei in the sarcolemma. (Haematoxylin and eosin.)

Fig. 3 Atrophy and necrosis in types of muscle fibres (ATPase, pH 4.6). Type I fibres are more opaque than type II. and there was no evidence of an inflammatory reaction. Fuchsin-stained deposits were not seen on trichrome preparations. Four fibre types were revealed by ATPases (Fig. 3): type I, IIa, IIb, and a few type IIc. The fibre types were normally distributed in a mosaic pattern. The observed lesions did not selectively involve a given type of fibre. The phosphorylase reaction was normally positive and, excluding necrotic fibres, the muscle fibre contents were unmodified on PAS staining. Nerve fibre morphology was normal in biopsy specimens. Ultrastructural analysis also showed necrotic lesions and a large number of regenerative muscle fibres. The above manifestations confirmed the diagnosis of progressive Duchenne type muscular dystrophy.

\section{Discussion}

Diagnosis of Duchenne type muscular dystrophy. was based on clinical, biochemical, and histological grounds in this patient. The complete and early expression of the disease in a young girl could be explained by several hypothetical genetic mech anisms.

The first hypothetical explanation is that tran 80 mission occurred in an autosomal recessive moder especially since the parents are first cousins and paternity was verified. This proposal implies thळ coexistence of a mutant autosomal recessive gene an $\$$

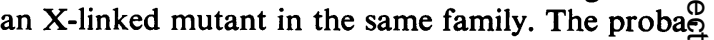
bility of such an event is, of course, extremely low 
A second possible explanation is that the proband was homozygous for the $\mathrm{X}$-linked gene, the paternal $\mathrm{X}$ chromosome having undergone a germinal mutation. In this case, the probability is related to the mutation rate of the gene, which is of the order of $50 \times 10^{-6}$ according to Danieli et al. (1977).

Thirdly, an anomaly involving gonosomal number or structure might be the cause. We can eliminate this hypothesis: 50 mitoses in cultured lymphocytes were analysed after mild heat denaturation and no abnormalities were observed. Finally, the degree of phenotypic expression in a girl heterozygous for the $\mathrm{X}$-linked gene can be invoked as a possible explanation. Other workers have previously reported the presence of clinical symptoms in female carriers (Emery, 1963; Johnston, 1964; Murphy et al., 1965; Penn et al., 1970; Stern, 1972; Zatz et al., 1973; Moser and Emery, 1974). Girls are only very rarely affected as severely as boys (Johnston, 1964; Penn et al., 1970; Gomez et al., 1977). Such diversity in clinical expression may be accounted for by Lyonisation of the $\mathrm{X}$ chromosomes in the muscle cells of girls heterozygous for the myopathic gene. Several authors have proposed this hypothesis (Emery, 1963; Murphy et al., 1965; Zatz et al., 1973; Moser and Emery, 1974; Gomez et al., 1977). We have no cytogenetic or biochemical criteria to confirm that there is a majority of active $\mathbf{X}$ chromosomes containing the myopathic gene in carriers with complete phenotypic expression, whereas such criteria have been established in haemophilia (Graham et al., 1975). If, however, the Lyon hypothesis were proved to take place in muscular dystrophy, the preceding proposal would be feasible. Indeed, an infinite range of combinations between paternal and maternal inactivated $\mathrm{X}$ chromosomes is possible in carriers. The number of different clinical states and their probability of occurring would then depend on the number of future muscle cells in the zygote when inactivation occurs.

Confronted by the diversity of hypothetical genetic mechanisms that remain plausible, we can only offer the parents a relatively limited form of genetic counselling: the probability of having an affected son is $1 / 2$ and that of having an affected daughter, though not certain, is not nil. For example, Moser and Emery (1974) suggest that perhaps $8 \%$ of carriers may have manifestations, so the chance of having a daughter who might show at least some manifestation may be as high as $4 \%$.

Ségolène Aymé, J. F. Pelissier, J. M. Garnier, J. F. Mattei, ANd F. GiRaud Travail du Centre de Génétique Medicale, Hôpital d'Enfants, Groupe Hospitalier de la Timone, 13385 Marseille Cedex 4, France

\section{References}

Danieli, G. A., Mostacciuolo, M. L., Bonfante, A., and Angelini, C. (1977). Duchenne muscular dystrophy. A population study. Human Genetics, 35, 225-232.

Emery, A. E. H. (1963). Clinical manifestations in two carriers of Duchenne muscular dystrophy. Lancet, 1, 1126.

Gomez, M. R., Engel, A. G., Dewald, G., and Peterson, H. A. (1977). Failure of inactivation of Duchenne dystrophy Xchromosome in one of female identical twins. Neurology, 27, 537-541.

Graham, J. G., Barrow, E. S., and Elstom, R. C. (1975). Discussion paper: Lyonization in hemophilia: a cause of error in direct detection of heterozygous carriers. Annals of the New York Academy of Sciences, 240, 141-146.

Johnston, H. A. (1964). Severe muscular dystrophy in girls. Journal of Medical Genetics, 1, 79-81.

Moser, H., and Emery, A. E. H. (1974). The manifesting carrier in Duchenne muscular dystrophy. Clinical Genetics, 5, 271-284.

Murphy, E. G., Thompson, M. W., Corey, P. N. J., and Conen, P. E. (1965). Varying manifestations of Duchenne muscular dystrophy in a family with affected females. Muscle. Proceedings of a Symposium at the Faculty of Medicine, University of Alberta, pp. 529-546. Pergamon Press, New York.

Penn, A. S., Lisak, R. P., and Rowland, L. P. (1970). Muscular dystrophy in young girls. Neurology, 20, 147-158.

Stern, L. M. (1972). Four cases of Duchenne type muscular dystrophy in girls. Medical Journal of Australia, 59, 10661069.

Zatz, M., Levisky, R. B., Levy, J. A., Valente, B. O., Gianotti, M., and Frota-Pessõa, O. (1973). Clinical symptoms in a female carrier of Duchenne muscular dystrophy. Journal de Génétique Humaine, 21, 297-305.

Requests for reprints to Dr S. Aymé, Centre de Génétique Medicale, Hôpital d'Enfants, Groupe Hospitalier de la Timone, 13385 Marseille Cedex 4, France.

\section{A case of partial trisomy 17 resulting from $\mathrm{X}$-autosomal translocation ${ }^{1}$}

SUMMARY A case of partial trisomy 17 with partial monosomy $X$ resulting from a maternal $X$-autosomal translocation $t(X ; 17)(q 13 ; q 21)$ is presented. Three previously reported cases are reviewed and the phenotypic features of trisomy 17 are discussed.

Since banding techniques were introduced, three cases of trisomy 17, with different degrees of imbalance of the genetic material, have been reported. We present a new case of partial 17 trisomy with partial monosomy $\mathrm{X}$, which was the result of a familial reciprocal translocation.

${ }^{1}$ This study was supported in part by a grant from the Ministry of Health and Welfare of Japan for research on handicapped children, 1977. 